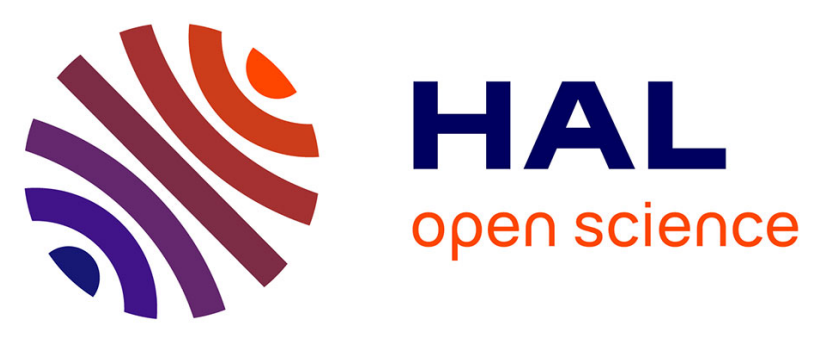

\title{
Elucidating in utero fetal demise time to reassemble the pieces of the puzzle?
}

Nicolas Belhomme, Alain Lescoat, Alice Ballerie, Florence Rouget, Gwenaelle Le Bouar, Philippe Loget, Leïla Caillault, Patrick Jégo

\section{- To cite this version:}

Nicolas Belhomme, Alain Lescoat, Alice Ballerie, Florence Rouget, Gwenaelle Le Bouar, et al.. Elucidating in utero fetal demise time to reassemble the pieces of the puzzle?. Journal of Maternal-Fetal \& Neonatal Medicine, 2020, 18 (21), pp.1-3. 10.1080/14767058.2019.1580262 . hal-02061953

\section{HAL Id: hal-02061953}

\section{https://hal-univ-rennes1.archives-ouvertes.fr/hal-02061953}

Submitted on 22 Mar 2019

HAL is a multi-disciplinary open access archive for the deposit and dissemination of scientific research documents, whether they are published or not. The documents may come from teaching and research institutions in France or abroad, or from public or private research centers.
L'archive ouverte pluridisciplinaire HAL, est destinée au dépôt et à la diffusion de documents scientifiques de niveau recherche, publiés ou non, émanant des établissements d'enseignement et de recherche français ou étrangers, des laboratoires publics ou privés. 
The Journal of Maternal-Fetal and Neonatal Medicine Correspondence Letter

\section{Elucidating In Utero Fetal Demise: Time to reassemble the pieces of the puzzle?}

Nicolas Belhomme $\mathrm{MD}^{1,2}$, Alain Lescoat MD MSc ${ }^{1,3}$, Alice Ballerie $\mathrm{MD}^{1,3}$, Florence Rouget $\mathrm{MD}^{2,3}$, Gwenaelle Le Bouar MD ${ }^{2,4}$, Philippe Loget MD ${ }^{2,5}$, Leila Caillault MD ${ }^{1}$, Patrick Jego MD $\mathrm{PhD}^{1,3}$

1- Department of Internal Medicine and Clinical Immunology, CHU Rennes, University of Rennes 1, Rennes, France

2- Perinatal network, CHU Rennes, University of Rennes 1, Rennes, France

3- University of Rennes, CHU Rennes, Inserm, EHESP, Irset (Institut de recherche en santé, environnement et travail) -UMR_S 1085, F-35000 Rennes, France

4- Department of Obstetrics and Gynecology, CHU Rennes, University of Rennes 1, Rennes, France

5- Department of Pathology, CHU Rennes, University of Rennes 1, Rennes, France

Conflicts of Interest: None

Corresponding author: Nicolas Belhomme, Department of Internal Medicine, CHU Rennes, South Hospital, 16 bvd de Bulgarie - 35203 RENNES Cedex 2 - BP 90347

E-Mail : nicolas.belhomme@chu-rennes.fr

Phone: +33299267128 fax : +33299267198

Words count: 957 


\section{Elucidating In Utero Fetal Demise: Time to reassemble the pieces of the puzzle?}

To the editor:

We read with great interest the article by A Manocha et al. [1] recently published in the JFMNM. Through a standardized pathological review, the authors give an interesting insight into the placental findings in a series of 100 intrauterine fetal demise (IUFD) cases, before extending their analysis to determine the plausibility of each pathological finding to contribute to IUFD. They conclude that among all histological patterns, maternal vascular malperfusion (MVM) is the most frequent etiology of IUFD, pregnancy hypertensive disorders being -as a matter of factwidely encountered.

Acknowledging that placental pathology constitutes a cornerstone of IUFD management, looking at the results of Manocha and colleagues' work beyond the pathologist's lens may offer new perspectives and may also broaden their conclusions.

In their work, the authors report a high prevalence of pre-eclampsia which was found in $39 \%$ of IUFD case, while a rate of $9.2 \%$ was found in other studies [2]. Moreover, in the definition of pre-eclampsia chosen by the authors, proteinuria needed to be associated with an elevation of blood pressure. This definition is more restrictive than the latter proposed by the ACOG in 2013 [3] and the true prevalence of preeclampsia according to this latter definition may even be higher. Thus, this high prevalence of pre-eclampsia - even possibly underestimated raises two issues:

a) it may illustrate that placentas are more commonly addressed to the pathologist when IUFD occurs in a context of pre-eclampsia than in the other IUFD cases. This assumption would need to be verified and, if so, may convey an evolution of practices in the field: as well illustrated by the authors, placental examination is the cornerstone of IUFD management [4], this being particularly true in the absence of maternal clinical context (e.g: pre-eclampsia, sepsis...) providing relevant etiological orientations.

b) Consequently, placental data need to be interpreted in the light of a global and exhaustive IUFD assessment, including the collection of all pre-eclampsia risk factors. Indeed, from a pathogenic view-point, it has been proposed to distinguish early and late onset preeclampsia which, despite the similarity of their pathological presentation, differ in term of pathogenesis - i.e. immune incompatibility for the former, global maternal cardiovascular burden 
for the latter - and their outcomes, both regarding the risk of recurrence and the efficacy of prevention, and also probably in the related long-term maternal cardiovascular over-risk [5].

Conversely, the authors observed a high rate of early IUFD linked to MVM lesions: in all apparently unexplained case of IUFD, especially of early preterm onset [6], a search for thrombophilia should be performed, as mentioned by the authors. Actually, this evaluation should be limited to antiphospholipid antibodies (APL) and lupus anticoagulant testings, as there is no clear evidence of the impact of inherited thrombophilia on pregnancy loss, as well as of the efficacy of anticoagulants in these situations [7]. Along with APL, antinuclear antibody (ANA) testing is also recommended, combined with a thorough maternal clinical evaluation, given the association between systemic lupus erythematosus (SLE) and IUFD [8]. Moreover, the search for antiphospholipid antibodies syndrome or other autoimmune disorders may be of great interest with possible far reaching consequences:

- In terms of pathogenesis, separating the patients into different groups not only based on histological considerations - a type of lesion being possibly the consequence of different phenomenon- but also on clinical and biological findings (i.e. definite APLS, atypical or noncriteria APLS, ANA) is a prerequisite for a close to reality approach of the pathogenic processes leading to maternal vascular complications;

- From nosological and etiological viewpoints, a more global and holistic approach may contribute to reframe the classification of IUFD etiologies and to precise the prevalence of auto-immune features as a cause for IUFD. For example, considering MVM lesions in a proven/definite APLS setting should lead to retain the IUFD as from maternal cause rather than from a placental cause, the placental abnormalities being here a manifestation of a maternal immune mediated disease [9]. The same goes for inflammatory lesions, that is to say chronic villitis, and more importantly intervillositis. Indeed, their individualization is important as, once infectious etiologies have been carefully ruled-out, there is growing evidence to support their involvement in adverse obstetric outcomes and their association with autoimmune disorders [10];

- In a diagnostic perspective, IUFD may, in rare cases, reveal underlying systemic diseases, and a positivity of ANA may foster the search for other clinical or biological signs of autoimmune disorders and, even in the absence of such signs, may constitute an alarm to carefully screen their emergence in the future for a patient with a history of IUFD and positive ANA.

- Most importantly, as concluded by the authors in a therapeutic viewpoint, determining the cause of IUFD aims to better manage future pregnancies. So far, only few standardized 
treatment regimens have proven to be efficient to limit IUFD recurrence: aspirin in preeclampsia, the association of aspirin and heparin in obstetrical APLS, and hydroxychloroquine in SLE (topped by heparin and/or aspirin in cases of associated APLS or in selected high-risk women) [11,12]. Beside these specific cases, data are cruelly missing, and the best therapeutic approaches in pregnancies following MVM or inflammatory lesions related IUFD still need to be determined.

Brightening the dark zones of IUFD etiologies constitutes a challenge which raises the need for developing collaborative networks uniting gynecologists, pediatricians, pathologists, immunologists and internists. Indeed, a close multidisciplinary approach, along with an exhaustive etiological assessment and a classification system integrating the whole relevant data, may constitute a unique opportunity to think outside the box, fostering new innovative therapeutic research for this still poorly understood condition. Beyond considerations based on placental histology, a call for structured multidisciplinary approaches and collaborative networks may represent a turn of the tide to give to IUFD the attention it deserves.

\section{REFERENCES:}

[1] Manocha A, Ravikumar G, Crasta J. Placenta in intrauterine fetal demise (IUFD): a comprehensive study from a tertiary care hospital. J Matern Fetal Neonatal Med. 2018;6:1-9.

[2] Stillbirth Collaborative Research Network Writing Group. Causes of death among stillbirths. JAMA. 2011;306:2459-68.

[3] Hypertension in pregnancy. Report of the American College of Obstetricians and Gynecologists' and Task Force on Hypertension in Pregnancy. Obstet Gynecol. 2013;122:112231.

[4] Heazell AE, Martindale EA. Can post-mortem examination of the placenta help determine the cause of stillbirth? J Obstet Gynaecol. 2009;29:225-8.

[5] Redman CW, Sergent IL. Latest advances in understanding preeclampsia. Science 2005;10: 308:1592-4.

[6] Miyakis S, Lockshin MD, Atsumi T, et al. International consensus statement on an update of the classification criteria for definite antiphospholipid syndrome (APS). J Thromb Haemost. 2006;4:295-306. 
[7] Bennett SA, Bagot CN, Arya R. Pregnancy loss and thrombophilia: the elusive link. Br J Haematol. 2012;157:529-42.

[8] Bundhun PK, Soogund MZ, Huang F. Impact of systemic lupus erythematosus on maternal and fetal outcomes following pregnancy: A meta-analysis of studies published between years 2001-2006. J Autoimmun. 2017;79:17-27.

[9] Frøen JF, Pinar H, Flenady V et al. Causes of death and associated conditions (Codac): a utilitarian approach to the classification of perinatal deaths. BMC Pregnancy Childbirth 2009;10:9-22.

[10] Mekinian A, Costedoat-Chalumeau N, Masseau A, et al. Chronic histiocytic intervillositis: outcome, associated diseases and treatment in a multicenter prospective study. Autoimmunity 2015;48:40-5.

[11] de Jesus GR, Agmon-Levin N, Andrade CA, et al. 14th International Congress on Antiphospholipid Antibodies Task Force report on obstetric antiphospholipid syndrome. Autoimmun Rev. 2014;13:795- 813.

[12] Andreoli L, Bertsias GK, Agmon-Levin N, et al. EULAR recommendations for women's health and the management of family planning, assisted reproduction, pregnancy and menopause in patients with systemic lupus erythematosus and/or antiphospholipid syndrome. Ann Rheum Dis. 2017;76:476-485. 